\title{
BIOLOGÍA DE SISTEMAS Y LA MEDICINA DEL FUTURO
}

\section{LEROY HOOD}

VERANO DE $2004 \bullet$ BAT TEN B RIEFIN GS

Un debate trimestral sobre innovación, empresa y transformación empresarial.

Para el año 2015 la atención médica será muy distinta de lo que es actualmente. Por ejemplo, en lugar de visitar al médico en su consultorio, donde una enfermera nos extrae una muestra de sangre que luego enviará al laboratorio y allí un técnico realizará menos de 20 mediciones, muchos de nosotros utili-

\section{RESUMEN}

La biología de sistemas anuncia cambios de gran importancia en la Medicina y las disciplinas asociadas a ella. Gracias a la aplicación de nuevos desarrollos tecnológicos será posible el estudio de sistemas biológicos y el pronto análisis de unidades de información (ADN o sus genes y proteínas). Con ayuda de aparatos electrónicos y digitales se explorará de manera rápida y exhaustiva el cuerpo de una persona. La nanotecnología que cuenta ya con el aporte de biólogos, químicos, científicos de computadoras, ingenieros, matemáticos y físicos podrá ser manipulada incluso por los propios pacientes.

La medicina será, entonces, personalizada y tendrá un importante componente $\mathrm{pr}_{3}$-ictivo, que impedirá el desarrollo de enfermedades. Es un cambio de paradigma que abrirá, además, nuevas posibilidades de negocios, reemplazará, en parte, los métod-os tradicionales de diagnóstico y curación, pero exigirá asumir serios compromisos éticos.

\section{ABSTRACT}

The author's experience as one of the most innovative professionals in the biology field and his increasing understanding of every new change in this area turns this encouraging and surprising article a must to understand on which way is science going at this time and its short-term results. System Biology, together with technological developments, will allow, for example, the complete understanding of the human body and will make the medicine a predictive and preventive science. In other words, it will be possible - through the use of devices - to discover the possibility to develop an illness and take up its treatment ten or fifteen years in advance; likewise, the productive life span of the ordinary person will probably be ten to 20 years longer.

This is only one among many possibilities as it will facilitate the development of new drugs to anticipate the nature of the side effects. It will also unveil a wide range of business possibilities in medical and health attention, agriculture, nutrition, etc., which will solve many of the problems now afflicting our world. 
zaremos un dispositivo de mano de "nanotecnología" que puede pinchar un dedo y efectuar 1.000 mediciones a partir de una gota de sangre. Tales mediciones que se captan en minutos, se enviarán a través de un teléfono celular a un servidor que las analizará para luego enviar un mensaje electrónico el cual dirá algo así como: "Usted está bien; repita este procedimiento en seis meses", o "solicite una cita con el oncólogo".

Este será un procedimiento de rutina en la nueva era de la medicina, una era anunciada por la biología de sistemas: el estudio de un sistema biológico a través del análisis de sus elementos. El nuevo enfoque trasformará la medicina y con ella el sistema de asistencia médica y muchos otros aspectos de la sociedad.

En el último número de Batten Briefings ${ }^{1}$ escribí sobre mi experiencia a la vanguardia de la biología y mi convicción de que todo nuevo cambio de paradigma en un campo específico requiere de una nueva estructura organizacional para obtener el debido crecimiento. Continuaré explorando el tema a medida que vaya cubriendo el cambio de paradigma en la biología de sistemas, las nuevas y poderosas tecnologías y herramientas de computación, los mandatos de la nueva biología, la medicina predictiva, preventiva y personalizada del futuro y las oportunidades y cuestionamientos que la nueva biología y la nueva medicina presentan al mundo empresarial y a la sociedad en general.

\section{¿QUÉES BIOLOGÍA DE SISTEMAS?}

Si desea comprender cómo opera la atención de la salud, resulta sensato estu- diar la forma como las partes de este complejo sistema - doctores, enfermeras y todos los demás profesionales de la salud, hospitales, compañías de seguro, el gobierno, las industrias farmacéuticas y de dispositivos médicos - trabajan en conjunto, al igual que las interacciones dentro de cada grupo.

La biología de sistemas promueve un tipo similar de entendimiento del cuerpo humano, al analizar los diferentes tipos de unidades de información biológica (ADN o sus genes y proteínas) para revelar cómo funciona un sistema biológico, como por ejemplo, la respuesta inmune. Mientras que la biología tradicional se concentra al mismo tiempo en uno o en sólo unos pocos genes o proteínas, la biología de sistemas trata de entender la forma cómo gran cantidad de genes y proteínas actúan conjuntamente.

El entendimiento de los sistemas biológicos comienza con el entendimiento del papel del ADN y de los genes, el código fuente de la vida. Cada uno de los 30.000 genes humanos codifica una proteína específica. Las proteínas son las máquinas moleculares que catalizan la química de la vida y le dan forma y composición al cuerpo. Cuando se examina a otra persona, todo lo que uno ve es proteína. Hace relativamente poco los biólogos se dieron cuenta que las proteínas casi nunca trabajan solas; interactúan entre sí y con otras moléculas para crear sistemas o redes (como la red de conexiones de internet). Para estudiar estas interacciones, increíblemente complejas - la actividad central de la biología de sistemas - se necesitan herramientas nuevas que en forma económica puedan efectuar mediciones rápida y exhaustiva-

1 Hood, Leroy. “New Ideas Thrive on New Organizational Structures”. Batten Briefings Institute,Volume 3, Number 2, Spring 2004. 
mente. También se requieren nuevas herramientas matemáticas para integrar y analizar esta información y al final delinear las interacciones como redes que explican los comportamientos de los sistemas biológicos.

La biología de sistemas se basa en la premisa de que la ciencia y la tecnología están ligadas inextricablemente y que la biología puede trascender sus propias fronteras al impulsar el desarrollo de nuevas tecnologías. Esto representa un giro enorme de la biología tradicional, que siempre ha considerado la alta tecnología como una distracción y, en general, no ha buscado activamente sinergias con otras disciplinas. Desarrollar las herramientas de la biología de sistemas es una empresa esencialmente interdisciplinaria que exige la cooperación de biólogos, químicos, científicos de computadores, ingenieros, matemáticos y físicos. Algo ya tratado en mi artículo anterior es que he descubierto que la biología de sistemas exige un nuevo tipo de organización porque hace que la gente trabaje en equipo en formas desconocidas. Con mis colegas del Institute for Systems Biology

\section{RESEÑA DEL AUTOR}

El doctor Leroy Hood es reconocido como uno de los más importantes científicos del mundo en biotecnología molecular y genómica. Cuenta con numerosas patentes y premios por sus avances científicos. Obtuvo su título de médico de Hopkins University en 1964 y en 1968 un doctorado en bioquímica de California Institute of Technology. Desde entonces, su investigación se ha centrado en el estudio de la biotecnología y la inmunología molecular. Ha publicado más de 500 trabajos evaluados por expertos, recibido doce patentes y ha sido coautor de libros de texto en bioquímica, inmunología, biología molecular y genética; es miembro de la National Academy of Sciences (Academia Nacional de Ciencias), de la American Philosophical Society (Sociedad Filosófica Americana) y de la American Association of Arts and Sciences (Asociación Americana de Artes y Ciencias). Actualmente es presidente del Institute For Sistem Biology en Seattle, Washington. Se le puede localizar en Ihood@systembiology.org.
(ISB), (Instituto de Biología de Sistemas), creamos nuestra organización para reunir personas que puedan progresar en el campo y desarrollar las tecnologías y herramientas de computación que requiere la biología de sistemas. ISB ha presentado a otros biólogos toda una nueva forma de practicar su disciplina, lo cual ha sido fundamental para permitir un progreso rápido en el campo.

\section{PREDICCIÓN, PREVENCIÓN Y PERSONALIZACIÓN DE LA MEDICINA}

La biología de sistemas cambiará fundamentalmente la medicina. Es un giro que se puede denominar "cambio de paradigma". La medicina de hoy es reactiva: esperamos a que una persona se enferme para tratarla. La medicina del futuro será predictiva y preventiva, y examinará la biología de un individuo para evaluar la probabilidad de enfermedad y sugerir el tratamiento adecuado. La medicina de hoy no es muy rica en parámetros; utiliza pocas mediciones para evaluar la enfermedad y, por lo tanto, no hace distinciones perfectas entre los individuos. La medicina del futuro será de múltiples parámetros. Utilizará exponencialmente más mediciones que pueden arrojar evaluaciones y tratamientos médicos altamente personalizados.

Tengamos en cuenta este hecho: las enfermedades son el resultado de genes defectuosos o de un estímulo ambiental patológico, como los organismos infecciosos. La presencia de ciertos genes defectuosos puede conllevar predicciones probabilísticas sobre la salud de un individuo. Por ejemplo, si usted es una mujer con un solo ejemplar del gen mutante uno del cáncer de mama, tiene un $70 \%$ de posibilidad de desarrollar cáncer de mama antes de cum-
La biología de sistemas se basa en la premisa de que la ciencia y la tecnología están ligadas inextricablemente y que la biología puede trascender sus propias fronterasal impulsarel desarrollo de nuevas tecnologías. 
plir los 60 años. Actualmente, la mayoría de nosotros tenemos poca probabilidad de descubrir si tenemos un gen defectuoso. En el futuro, obtendremos esa información con facilidad. La verdad es que la medicina estará impulsada por ella.

Consideremos cada uno de los aspectos de la nueva medicina. El primero, predic-

determinación de la secuencia del genoma de cada individuo dependerá de un dispositivo de nanotecnología que puede ordenaren forma lógica todo el genoma humano en unafracción de horapor menos de US\$1.000; esta herramientase podráadquirir en los próximos diez a 15 años. ción. Tendremos a nuestra disposición dos tipos diferentes de información a través del uso de tecnologías y herramientas de la biología de sistemas. Al examinar la composición genética de un individuo (estableciendo el orden lógico de todo el genoma), los médicos estarán en condiciones de generar una predicción exhaustiva de su salud. Y, al examinar la sangre de una persona, el médico podrá evaluar su estado de salud actual: los genes y el estímulo ambiental, las dos respuestas que predisponen a enfermedades. La determinación de la secuencia del genoma de cada individuo dependerá de un dispositivo de nanotecnología que puede ordenar en forma lógica todo el genoma humano en una fracción de hora por menos de US\$1.000; esta herramienta se podrá adquirir en los próximos diez a 15 años. La secuencia del genoma de cada individuo servirá de base para un análisis generado por computador sobre la naturaleza de cada uno de los 30.000 genes y hará posible varias predicciones. Por ejemplo, como tiene ciertos genes defectuosos, existe el $40 \%$ de posibilidad de que usted desarrolle cáncer de mama antes de los 50 años, y $80 \%$ de probabilidad de desarrollar enfermedades cardiovasculares antes de los 65. El análisis de sangre depende del dispositivo de mano que mencioné anteriormente. Las personas lo utilizarán cada seis meses para efectuar 1.000 mediciones, lo cual actuará como una ventana para ver su estado actual de salud. Ese análisis de múltiples parámetros será uno de los distintivos de la nueva era de la medicina; nos permitirá estratificar una enfermedad en sus diferentes tipos (por ejemplo, existen actualmente tres o más tipos de cáncer de próstata, pero solo el análisis multiparamétrico permite a los científicos distinguirlos entre sí), diagramar el avance de la enfermedad, hacer seguimiento a su tratamiento con un medicamento y medir los efectos secundarios del mismo.

Miremos ahora la prevención que es el siguiente paso lógico. El objetivo de la nueva medicina será utilizar toda la información biológica de un individuo - la secuencia inicial del genoma más las valoraciones actuales y en curso de su salud - para hacer uso de los medicamentos preventivos correspondientes. Por ejemplo, puede que usted tenga el $40 \%$ de posibilidad de desarrollar cáncer de mama antes de los 50, pero si comienza a tomar cierto medicamento a los 35 , la posibilidad disminuye a un $5 \%$. Es posible que en los próximos cinco a 15 años, los biólogos de sistemas puedan distinguir las redes normales de vida de aquellas afectadas, e identificar proteínas en la red afectada que, de ser perturbada por un medicamento, pueda revertir la red enferma a una más normal. Entonces esas proteínas se convierten en referencia para el desarrollo de fármacos. De esta forma la biología de sistemas ofrece un planteamiento razonable para el descubrimiento de medicamentos de referencia. Los científicos también podrán detectar cambios en los niveles de otras proteínas ocasionados por los nuevos medicamentos que aumentan la posibilidad que la persona desarrolle efectos secunda- 
rios perjudiciales. Así, los nuevos enfoques mostrarán no sólo la posibilidad de ciertas enfermedades, sino también cómo responderá el paciente a varios tratamientos. El tema relevante - la capacidad predictiva y preventiva de la nueva era de la medicina - es la personalización. En promedio, cada ser humano difiere de otro en seis millones de letras del lenguaje de ADN. Muchas de estas diferencias son irrelevantes, pero algunas codifican nuestras diferencias físicas y otras pocas codifican nuestra predisposición a varias enfermedades. La posibilidad de examinar todas nuestras diferencias genéticas $y$, por ende, personalizar nuestra posición frente a las enfermedades y su tratamiento, será el centro de este cambio en el paradigma médico.

\section{LAS OPORTUNIDADES COMERCIALES}

La medicina predictiva, preventiva y personalizada, virtualmente transformará cada componente del sistema de atención médica-sanitaria, incluso la educación médica. Existen muchas oportunidades comerciales detrás de estos cambios revolucionarios. Este es un ejemplo. La industria farmacéutica tendrá $\$ 80$ mil millones de dólares en medicamentos cuyas patentes vencen antes del 2008, pero los medicamentos que actualmente se encuentran en preparación tan solo reemplazarán una fracción mínima de esa cantidad. La biología de sistemas será crucial en el proceso de descubrimiento de medicamentos: no sólo constituye una poderosa herramienta para identificar las proteínas específicas que serán eficaces medicamentos de referencia, sino que también revela - mucho antes de la larga y costosa etapa de los ensayos clínicos - la naturaleza de los efectos secundarios del nuevo medicamento. En realidad, la mayoría de las enfermedades son tan complejas biológicamente que las posibilidades de identificar referencias eficaces para fármacos sin la ayuda de sistemas, es bastante reducida. Aún así, la industria farmacéutica no está haciendo biología de sistemas, en parte, porque las herramientas aún están en proceso de desarrollo y, en parte, porque los laboratorios farmacéuticos, con sus estrechos silos funcionales, no son adecuados para las funciones cruzadas que exige la biología de sistemas. Como resultado de esto, el proceso de descubrimiento está fallando.

La pregunta es si la industria farmacéutica puede adoptar los planteamientos de la biología de sistemas, o si el descubrimiento de fármacos provendrá en el futuro de las compañías de biología de sistemas que tienen la estructura multidisciplinaria apropiada, tecnologías integradas y la pericia computacional y matemática. Un escenario, que yo considero muy probable, siguiendo con el argumento que las ideas nuevas exigen nuevas estructuras de organización, es donde la industria farmacéutica integrada verticalmente migre hacia una integración y especialización más horizontal. Esto es exactamente lo que sucedió con la tecnología informática. En lugar de una industria compuesta por grandes compañías que pretenden hacer todo, tenemos a Microsoft que desarrolla software, a Intel especializada en chips, a Oracle, en bases de datos, y a Cisco con enrutadores. Las compañías farmacéuticas pueden terminar especializándose en ensayos clínicos y en la venta de fármacos, y una o más compañías de biología de sistemas, en su descubrimiento. En cualquier caso, exis- 
Consideremos que en los próximos veinte a treinta años, y como resultado de la nueva medicina, el periodo de vida productiva de una persona comúny corriente posiblemente será entre diez y 20 años más. tirán formidables oportunidades para los empresarios que reconozcan la naturaleza de estos cambios sorprendentes y avancen hacia su capitalización. He aquí otro ejemplo. Es obvio que la industria de atención médica-sanitaria del futuro tendrá una increíble necesidad de manejar cantidades masivas de información. Por ejemplo, sólo en los Estados Unidos, quizá 300 millones de secuencias completas de genoma (cada una de tres mil millones de letras) y ensayos semestrales de sangre de más de mil componentes para cada individuo. También tendrá que analizar esta información y enviarla a los correspondientes destinatarios (pacientes, médicos, etc.). Habrá una oportunidad enorme para que una o varias compañías de software ofrezcan estos servicios permanentes. El potencial para otro Microsoft está en gestación. Además de la atención médica-sanitaria, la tecnología de sistemas para la biología abrirá oportunidades sorprendentes en muchos otros campos. En la agricultura, por ejemplo, los científicos pueden usar una tecnología de sistemas integrados para obtener alimentos más nutritivos y que puedan cultivarse en varios climas. En nutrición, dicha tecnología podría revolucionar nuestro conocimiento acerca de los minerales y vitaminas necesarias para el cuerpo humano en las distintas etapas de la vida; un desarrollo que podría ayudar a transformar el tratamiento de deficiencias nutricionales en las regiones en desarrollo.

Adicionalmente, considerar los sistemas está catalizando las convergencias entre la biotecnología por un lado y las tecnologías informáticas, la nanotecnología y las ciencias de materiales por el otro. Por ejemplo, el estudio de las redes de vida revela que éstas tienen capacidades increíbles para integrar distinta información digital en formas muy complejas. No hay duda de que dichas estrategias suministrarán ideas a la comunidad tecnólogo-informática sobre cómo diseñar computadores y software más eficientes. Las aplicaciones de nanotecnología en la medicina y en la biología son evidentes en los dispositivos antes mencionados. Resulta justo señalar que la nanotecnología será una de las herramientas más revolucionarias para la biología y la medicina en los próximos cinco a veinte años. Los materiales que producen los organismos vivos proporcionan espléndidas oportunidades para idear los diseños de nuevos materiales para una amplia variedad de tareas. Por ejemplo, la seda que hilan las arañas es mucho más fuerte y ligera que el acero, y puede ser de gran utilidad en la ropa protectora de soldados y funcionarios encargados de hacer cumplir la ley. La biología de sistemas jugará un papel importante en la investigación sobre la forma como los seres vivos elaboran estos increíbles materiales y en la comercialización de las aplicaciones correspondientes.

\section{IMPLICACIONES SOCIALES}

La influencia de la nueva biología y la nueva medicina llegará a muchos rincones de nuestras vidas, nos tocará como individuos y como sociedad. Consideremos que en los próximos veinte a treinta años, y como resultado de la nueva medicina, el periodo de vida productiva de una persona común y corriente posiblemente será entre diez y 20 años más. Esto necesariamente tiene que transformar lo que pensamos sobre políticas de retiro y seguro médico y la percepción que tenemos del adulto mayor que puede 
ser creativo, productivo e interactivo a los ochenta, noventa y más allá.

La sociedad también se verá enfrentada a sorprendentes problemas éticos y legales (ninguno de ellos verdaderamente nuevo, pero sí de mayor magnitud): la inquietud de la privacidad genética y quién debe tener acceso a esa información; la pregunta sobre las células madre embrionarias con su enorme potencial para transformar los tratamientos médicos, y si el gobierno debe tener derecho a controlar el aspecto revelador de la ciencia por cuestiones religiosas (en contraposición a controlar las aplicaciones de esta ciencia); la cuestión de si es bueno desarrollar fármacos que extiendan la longevidad o conserven o amplíen la memoria.

La educación es crucial para ayudarnos a responder estas preguntas; se debe educar a todos los ciudadanos para que manejen, en forma muy responsable, los asuntos éticos y se debe guiar a las personas encargadas de elaborar las políticas. También debemos educar a la gente joven para que sea capaz de participar en una economía orientada, en gran parte, por las nuevas tecnologías basadas en la información. Y tenemos que educar a aquellos que pueden convertirse en los científicos impulsadores de la biología de sistemas hasta su límite y a los que van a crear el siguiente cambio de paradigma. La educación en ciencias en los Estados Unidos no cubre actualmente todos estos retos en una forma adecuada. Debe cambiar para los estudiantes de todos los niveles, pero tenemos que empezar con aquellos que darán forma al futuro del país: estudiantes K12 (primaria y secundaria). En las escuelas primarias sólo el $4 \%$ de los maestros ha tomado algún curso universitario de ciencias. En las escuelas de primaria y secundaria se tiende a enseñar esta asignatura mediante la memorización de detalles aburridos que con frecuencia no están actualizados. El Institute for Systems Biology (Instituto para Biología de Sistemas) está ensayando una reforma educativa sistémica de ciencias en todos los cursos de primaria y secundaria (K12) en Seattle y sus áreas aledañas, con el convencimiento de que todos los niños, independientemente de su raza, etnia o estatus socio económico, deben tener acceso a una buena educación en ciencias. Consideramos que todos los niños deben aprender a pensar a partir de la investigación y la consulta, lo que resulta de un planteamiento práctico de la ciencia. Cuando a los estudiantes se les da arcilla y agua, y se les pide diseñar un bote con máxima capacidad de transporte, aprenden rápidamente a plantear preguntas importantes y a trabajar a través de varios retos. Este tipo de pensamiento es de fundamental importancia para la gente joven, que tiene que ser capaz de manejar los desafíos de la nueva era médica, al igual que encontrar empleo en un mundo basado en la información. Educar a los maestros sobre cómo crear en sus estudiantes el pensamiento basado en la investigación, e incorporar los principios de la nueva biología serán pasos cruciales para el fortalecimiento de la educación en ciencias en las escuelas de primaria y secundaria del país.

\section{CÓMO SER UN EMPRESARIO EN EL MUNDO DE LA BIOLOGÍA DESISTEMAS}

Crear oportunidades de negocios a partir de los cambios masivos científicos, tecnológicos, médicos y sociales que se encuentran en curso exigirá de muchas de las mismas calificaciones y habilidades que
Educara los maestros sobre cómo crear en sus estudiantes elpensamiento basado en la investigación, e incorporar los principios de la nueva biología serán pasos cruciales para el fortalecimiento de la educación en ciencias en las escuelas deprimariay secundaria del país. 
En la biología

de hoy, uno de los conceptos

fundamentales es que la biología debe considerarse no como la ciencia de descripción yclasificación que se ha enseñado durante los últimos cien años, sino como una ciencia de la información. los empresarios deben aportar a cualquier situación: pasión, determinación, la capacidad para crear y comunicar una visión, la destreza para juzgar el talento, magnífico desempeño y aptitudes básicas de negocios. Pero para reconocer y formular las oportunidades creadas por la biología de sistemas también se necesita un tipo de conocimiento especial. En un campo como la biología de sistemas, en donde surgen continuamente tecnologías y herramientas computacionales, ser el primero en comercializarlas de ninguna forma garantiza el éxito. Lo que más importa es desarrollar un entendimiento sobre las cuestiones sociales y éticas del campo, al igual que de sus conceptos fundamentales.

En la biología de hoy, uno de los conceptos fundamentales es que la biología debe considerarse no como la ciencia de descripción y clasificación que se ha ense- ñado durante los últimos cien años, sino como una ciencia de la información. Un empresario que capte esta idea y aprenda sobre los diferentes tipos de información biológica, cómo se puede estudiar y cómo se puede integrar al entendimiento de los sistemas biológicos, podrá comprender los desafíos de los negocios y las oportunidades del futuro. Esta persona también estará equipada para explorar miles de posibilidades de negocios - sean estas de instrumentación médica, biotecnología o servicios médicos - y para construir la nueva estructura de organización que exigirá cada nueva oportunidad. Como todo periodo de gran transición, esta era biológica y médica en desarrollo presentará formidables oportunidades. Apoderarse de estas oportunidades exigirá un profundo entendimiento de la nueva biología. 